\title{
ENDOSCOPIC ENDONASAL DACRYOCYSTORHINOSTOMY: EXPERIENCE OF HUNDRED CASES
}

\author{
Muhammad Shahid, Muhammad Awais, Amjad Akram, Syed Abid Hassan Naqvi, Omar Zafar, Tahir Mumtaz Malik \\ Armed Forces Institute of Ophthalmology/National University of Medical Sciences (NUMS) Rawalpindi Pakistan
}

\begin{abstract}
Objective: To determine the success rate of Endonasal Endoscopic Dacryocystorhinostomy (Endo-DCR) in cases of chronic dacryocystitis secondary to primary acquired nasolacrimal duct obstruction (NLDO).

Study Design: Quasi-experimental study.

Place and Duration of Study: Department of Oculoplastic Surgery, Armed Forces Institute of Ophthalmology Rawalpindi, from Sep 2018 to Nov 2019.

Methodology: Endo-DCR under General Anaesthesia was performed on 100 patients of primary acquired nasolacrimal duct obstruction causing chronic dacryocystitis. Post-operatively these patients were checked on first post-op day, then on one week and finally four months after surgery. We removed silicone tubes of all the patients four months after surgery. To ensure patency of lacrimal passage, we did syringing and irrigation of lacrimal system of all cases, at conclusion of the study. We chose absence of epiphora and patent lacrimal system on syringing as indicators of successful procedure.

Results: Hundred patients (males 37; females 63) were recruited for this study. Mean age of our sample population was 51.1 \pm 29 years. Right nasolacrimal duct obstruction cases were 56 whereas left nasolacrimal duct obstruction cases were 44 . Subjective improvement i.e., absence of epiphora was found in $90 \%$ patients. We got successful irrigation of lacrimal passages (objective improvement) in $94 \%$ of patients.

Conclusion: Endo-DCR yields comparable results to external Dacryocystorhinostomy (Ex DCR). It offers additional benefits of esthetically better outcome, lesser complication rate and short surgery and patient recovery time.
\end{abstract}

Keywords: Chronic dacryocystitis, Endoscopic dacryocystorhinostomy, Mitomycin-C, Silicone stents.

How to Cite This Article: Shahid M, Awais M, Akram A, Naqvi SAH, Zafar O, Malik TM. Endoscopic Endonasal Dacryocystorhinostomy: Experience of Hundred Cases. Pak Armed Forces Med J 2021; 71(6): 2104-2108. Doi: https://doi.org/10.51253/pafmj.v71i6.4251

This is an Open Access article distributed under the terms of the Creative Commons Attribution License (https://creativecommons.org/licenses/by-nc/4.0/), which permits unrestricted use, distribution, and reproduction in any medium, provided the original work is properly cited.

\section{INTRODUCTION}

Dacryocystorhinostomy (DCR) is an established surgical modality for the treatment of epiphora secondary to nasolacrimal duct obstruction (NLDO). ${ }^{1}$ This procedure ensures continuity of lacrimal drainage system by creating a fistula between nasal cavity and lacrimal sac. An Italian ENT specialist, Addeo Toti is credited with the first description of DCR through external approach (EX-DCR) in 1904. ${ }^{2}$ External DCR is considered gold standard for treatment of NLDO because of its high success rate. However, Ex-DCR is not devoid of its limitations like presence of a cutaneous scar on nose, chances of damage to medial canthal structures and functional interference with the action of lacrimal pump. This led to the search for a lesser invasive technique to treat NLDO. Endoscopic DCR emerged as an effective alternative to EX-DCR. Advances in endoscopic visualization of nasal cavity, innovation of latest instruments, and enhancing clinical experience have made endoscopic DCR quite popular. It imparts $>90 \%$

Correspondence: Dr Muhammad Shahid, Classified Eye Specialist, Armed Forces Institute of Ophthalmology, Rawalpindi Pakistan Received: 04 May 2020; revision received: 11 Jun 2020; accepted: 22 Jun 2020 success rate along with esthetically more acceptable results. ${ }^{3}$ The indications of Endo-DCR are continuously evolving. In addition to its role in treating primary acquired NLDO due to chronic dacryocyctitis, Endo-DCR has proven efficacy in lacrimal sac abscess and nasolacrimal duct obstruction secondary to chemotherapy or radiotherapy. It is also being used as revision surgery for failed Ex-DCR. ${ }^{4}$ The topic of "Endonasl DCR" is increasingly being discussed in the international journals of ophthalmology and oculoplastic surgery. Search of published literature revealed that limited number of studies was conducted on local population in this regard. The purpose of this study is to determine the success rate of Endonasal dacryocystorhinostomy in local population suffering from primary acquired nasolacrimal duct obstruction.

\section{METHODOLOGY}

Hundred patients were included in this quasiexperimental study by non-probability convenience sampling technique. These patients underwent Endonasal Endoscopic Dacryocystorhinostomy, from September 2018 to November 2019. Ethical Review Committee of Armed Forces Institute of Ophthalmology 
(AFIO) granted approval for this study, vide reference letter no. 234/ERC/AFIO.

Inclusion Criteria: Cases of primary acquired nasolacrimal duct obstruction causing chronic dacryocystitis were included.

Exclusion Criteria: Cases of punctual stenosis, common canalicular blockage/scarring, ocular surface disorders, active ocular infections, large deviated nasal septum, severe facial disfigurement due to trauma and large nasal polyp were exclusion.

Patients with the complaint of epiphora and meeting inclusion/exclusion criteria were examined. We did syringing and lacrimal system irrigation of these patients. Thus, we chose patients with obstructed nasolacrimal duct. After obtaining the consent, these patients were assessed by a qualified anaesthetist. We operated all these patients under general anaesthesia in a slightly reversed Trendelenburg position (300) and under hypotensive general anaesthesia so that intraoperative bleeding may be lessened. Pre-Operatively, ribbon gauze was soaked in a solution of lignocaine plus adrenaline and nasal packing was done with it. In order to decongest nasal mucosa, $1 \mathrm{ml}$ of adrenaline in 1: 100,000 ratio was injected into the nasal mucosa just anterior to the axilla of middle turbinate. We used a $4 \mathrm{~mm}$ diameter $30^{\circ}$ nasal endoscope in all cases. The procedure began by creating and lifting a nasal mucosal flap which was posteriorly based and centered over the lacrimal sac area. The incision for this flap starts about $8 \mathrm{~mm}$ above the axilla of the middle turbinate. This incision is continued anteriorly on lateral nasal wall for about $8-10 \mathrm{~mm}$. A similar incision was made just above the inferior turbinate. A vertical incision joined these horizontal incisions anteriorly (Figure-1). With the help of a freer periosteal elevator, this flap of mucosa was then lifted off the lateral nasal wall. This flap is used to cover middle turbinate. Now frontal process of maxilla and lacrimal bone are visible for the next step i.e. osteotomy. Kerrison rongeurs were used to nibble and remove lacrimal bone and frontal process of maxilla in order to expose whole lacrimal sac and upper half of nasolacrimal duct. Usually the agar nasi cells are visible once the osteotomy is extended superiorly to expose upper-most part of lacrimal sac. A Bowman's probe is passed through punctum and is used to tent the medial wall of lacrimal sac which is seen via endoscope. Then we incised the medial wall of the lacrimal sac vertically and created small posterior and large anterior flaps of lacrimal sac. We made horizontal cuts in these flaps superiorly and inferiorly in order to reflect them onto the lateral nasal wall without any tension. Then a horizontal incision was made in the centre of large mucosal flap of lateral nasal wall in order to divide it into two halves. These flaps of nasal mucosa extend anteriorly from the posterior hinge. When placed on lateral nasal wall, these flaps cover most of the exposed bony ostium (Figure-2). Bicanalicular silicone stents were inserted through the punta and under endoscopic view, these were retrieved through nostril.

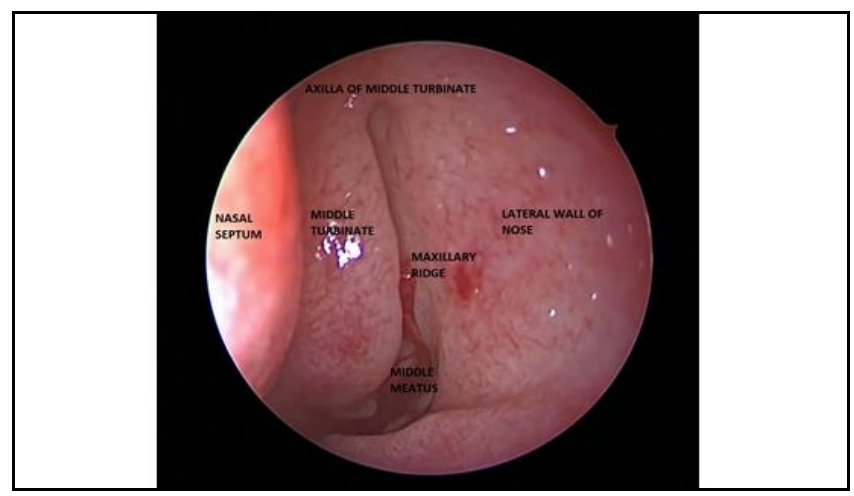

Figure-1: Endoscopic view of lateral wall of nose before Endonasal Dacryocystorhinostomy (DCR).

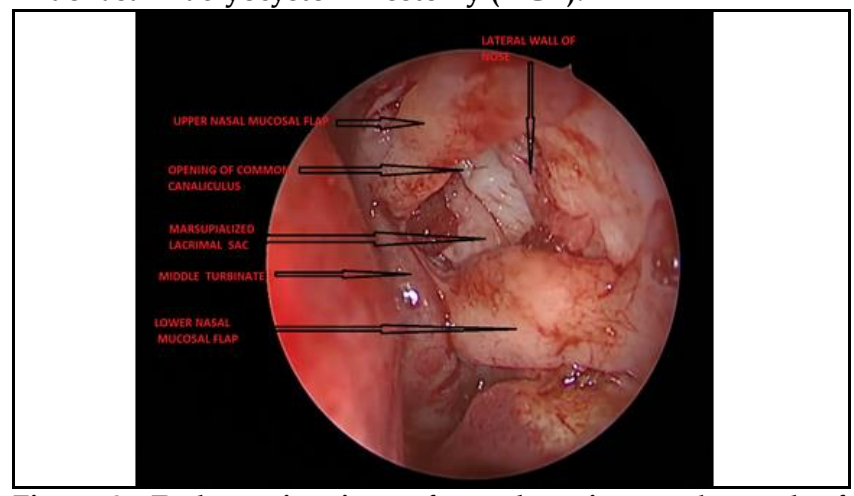

Figure-2: Endoscopic view of nasal cavity at the end of Endonasal Dacryocystorhinostomy (DCR).

At the end of surgery, ribbon gauze soaked in a solution of Lignocaine plus Adrenaline was used to pack nasal cavity for 24 hours in order to minimize post-operative bleeding from nasal mucosa. Patients were prescribed tablet Amoxycillin-Clavulanic acid, 625mg 8 hourly and tablet Diclofenac Sodium $50 \mathrm{mg}$ twice daily for 3 days. Moxifloxacin plus dexamethasone eye drops was recommended for topical use 6 hourly daily for one month. Nasal douching and Oxymetazoline nasal spray was recommended to use, thrice daily for 2 weeks. Patients were advised to come for follow-up on first post-operative day then one week and finally four months after surgery. Silicone tube was removed four months after surgery. In order 
to confirm patency of lacrimal system, we did syringing and irrigation of lacrimal passage after removing DCR tube. Success of Endo-DCR was determined as absence of discharge/epiphora from the puncta and absence of regurgitation of normal saline on irrigation of lacrimal system.

We noted variables like age, gender, post-op epiphora and post-op regurgitation. We used Statistical Package for Social Sciences (SPSS-25) for statistical analysis. Frequency and percentage of descriptive statistics like gender, post-operative epiphora and post-operative regurgitation was determined. By applying chisquare test, we tried to determine association between gender and post-operative epiphora and post-operative regurgitation. The $p$-value of $\leq 0.05$ was considered significant.

\section{RESULTS}

Hundred patients (males 37; females 63) underwent endoscopic endonasal DCR. Mean age of our sample population was $51.1 \pm 29$ years. In this study, 56 patients were suffering from right sided nasolacrimal duct obstruction whereas 44 patients were having left sided nasolacrimal duct obstruction. We checked absence of watering and successful irrigation of lacrimal system at the end of our study. We found absence of watering from eyes in $90 \%$ patients. Epiphora persisted in 10 patients (males 6; females 4); $p$-value was 0.112 which was insignificant. Post-operative epiphora occurred in 6 cases where right eye was operated and in 4 cases where left eye was operated. On irrigation of lacrimal passage, saline jet injected through punctum reached pharynx in 94 (94\%) patients showing objective improvement. Post-operative regurgitation of saline occurred in 6 patients (males 4; females 2), $p$-value was 0.121 which was insignificant (Table).

Table: Association between gender and post-operative epiphora and post-op regurgitation.

\begin{tabular}{|c|c|c|c|c|c|c|}
\hline \multirow[t]{2}{*}{ Gender } & \multicolumn{2}{|c|}{$\begin{array}{l}\text { Post-Operative } \\
\text { Epiphora }\end{array}$} & \multirow{2}{*}{$\begin{array}{c}p- \\
\text { value }\end{array}$} & \multicolumn{2}{|c|}{$\begin{array}{l}\text { Post-Operative } \\
\text { Regurgitation }\end{array}$} & \multirow{2}{*}{$\begin{array}{c}p- \\
\text { value }\end{array}$} \\
\hline & Yes & No & & Yes & No & \\
\hline Male & $\begin{array}{c}6 \\
(60 \%)\end{array}$ & $\begin{array}{c}31 \\
(34.4 \%)\end{array}$ & \multirow{2}{*}{0.112} & $\begin{array}{c}4 \\
(66.6 \%)\end{array}$ & $\begin{array}{c}33 \\
(35.3 \%)\end{array}$ & \multirow{2}{*}{0.121} \\
\hline Female & $\begin{array}{c}4 \\
(40 \%)\end{array}$ & $\begin{array}{c}59 \\
(65.6 \%)\end{array}$ & & $\begin{array}{c}2 \\
(33.4 \%)\end{array}$ & $\begin{array}{c}61 \\
(64.7 \%)\end{array}$ & \\
\hline
\end{tabular}

Post-operative regurgitation occurred in 5 cases where right eye was operated and 1 case where left eye was operated. Anatomical success rate in our sample population after Endo-DCR was $94 \%$.

Absence of post-operative epiphora and postoperative regurgitation were the determinants of success rate of Endoscopic DCR in our study.

\section{DISCUSSION}

Endoscopic endonasal dacryocystorhinostomy (Endo-DCR) is an effective alternative to external DCR in the treatment of nasolacrimal duct obstruction. This procedure gained popularity in the last two decades owing to its conspicuous advantages like esthetically more acceptable results due to absence of cutaneous scar on nose, preservation of lacrimal pump function, shorter procedure time and better visualization of nasal anatomy during procedure. ${ }^{5}$ This technique also gives ability to diagnose and treat endonasal pathology, such as septal deviation or middle turbinate hypertrophy. ${ }^{6}$ Caldwell first described the endonasal (non-endoscopic) approach in 1893 which later on, was modified by West in 1910, and Halle in 1914..$^{6-9}$ However, this approach fell out of favor due to inconsistent success rates. Inadequate visualization of the intranasal anatomy due to suboptimal surgical instruments and inadequate clinical experience were cited as the reasons for these inferior clinical outcomes. The modern description of endoscopic transnasal DCR was presented in 1989.10,11 Better endoscopic visualization of intranasal cavity with new instrumentation, and growing clinical experience has removed many of these concerns. Presently many authors are supporting endonasal endoscopic DCR because its success rate is comparable to that of external DCR.2,4,12 Many modifications and advancements in endonasal approach further enhanced its success. These include use of Diode lasers for making osteotomy, silicone stents, mitomycin-C and powered tools (high-speed drill and ultrasonic handpieces). ${ }^{6}$ The most common indication for Endo$\mathrm{DCR}$, so far, is primary acquired nasolacrimal duct obstruction.13,14 However, presently this procedure proved its role in the treatment of nasolacrimal duct obstruction in patients who have received chemotherapy or radiotherapy. It is also frequently used as revision surgery in cases of failed DCR. ${ }^{4}$

In this study, we did Endo-DCR procedure on 100 patients (male $37 \%$ and females 63\%). We noted that lacrimal sac problems are more common in females. ${ }^{15}$ Al-Asaadi SZ, in his study, reported that amongst the patients of NLDO, females were $68.75 \% .{ }^{16}$ Results of this study were close to ours. We got subjective improvement (absence of watering/epiphora) in $90 \%$ of patients and objective improvement (absence of regurgitation of normal saline on lacrimal system irrigation) in $94 \%$ of patients. Our results were comparable to those of Ex-DCR which are about $90-95 \%$ as reported by Ahmed et al. ${ }^{17}$ This high success rate is because of few 
factors. The operating ophthalmologist had good prehand knowledge of nasal anatomy and made osteotomy of adequate size. He also preserved and marsupialized mucosal flaps of lacrimal sac and inserted silicone stents at the end of procedure. Our results are supported by local and international published literature. Ahmed et al, published success rate of Endo-DCR up to $94.85 \% .{ }^{17}$ Aslam published subjective success rate of $95.3 \%$ and anatomical success rate of $96.2 \%$ after Endo-DCR. ${ }^{18}$ Ali published results of Endo-DCR performed on 196 patients. He published final anatomical success rate of $96.9 \%$ whereas functional success rate of $93 \% .{ }^{19}$ In all our cases, we preserved flaps of lacrimal sac mucosa and marsupialized them. However, some published literature presents comparable results after performing Endo-DCR without preserving mucosal flaps. For example, Kingdom TT published their results of Endo-DCR without preserving mucosal flaps, performed on 87 patients. They reported complete resolution of epiphora in $93.1 \%$ patients and objective anatomic patency in 3 (98\%).

Mitomycin-C is a systemic chemotherapeutic agent and slows wound healing by inhibiting the synthesis of collagen. Its topical application at osteotomy site during DCR retards formation of granulation tissue and adhesions ultimately preventing contracture of osteotomy site. Although we did not use it in any case, its adjunctive use in endoscopic DCR is considered by some to minimize the risk of complications and increase the success rate. Mjhi reported a success rate of 93.3\% after Endo-DCR with Mitomycin-C application as compared to the success rate of $86.67 \%$ without Mitomycin-C. ${ }^{20}$

Use of bicanalicular silicone tube at the end of Endo-DCR has also become debatable in recent years. Some authors reported that silicone stents maintain an open ostium leading to high postoperative patency rate. Contrary to it; others reported a greater failure rate due to silicone tube related complications. ${ }^{21}$ Orsolini et al in a meta-analysis reported a success rate of $94 \%$ after using silicone stents versus $90.6 \%$ without using them, thus favoring the use of stents. ${ }^{21}$ We routinely use silicone stents in all cases of DCR, believing that it enhances success rate. These stents are particularly useful in cases of canalicular stenosis, atrophic lacrimal sac and for re-operations. Some authors have reported comparable surgical outcome without using stents, ${ }^{22}$ because they assume that stents cause fibrosis and granulation tissue formation at osteotomy site. These stents may predispose to infections, adhesions, stent incarceration, canalicular lacerations and making false passage during intraoperative probing. Internationally published success rate of Endo-DCR ranges from 84$96 \% .{ }^{23-25}$ Thus results of our study were very much comparable with the published data. The strong aspects of this study are prospective design, adequate sample size and comparable results with the international studies.

\section{LIMITATION OF STUDY}

There was no comparison group in our study. Patientreported symptoms of epiphora were not validated on some scale.

\section{CONCLUSION}

Outcomes of endonasal endoscopic DCR are comparable with the best of external DCR. Appropriate selection of patient, better knowledge of endoscopic intra-nasal anatomy and site of lacrimal sac, creation of a large osteotomy exposing entire lacrimal sac, precise dissection of lacrimal sac, adequately exposing the common canalicular opening and correction of intranasal pathology if present can yield excellent long lasting results.

\section{Conflict of Interest: None.}

\section{Authors' Contribution}

MS: Surgical management of patients, MA: Manuscript writing, AA: Manuscript writing, SAHN: Surgical management of patients, OZ: Data evaluation, TMM: Data evaluation.

\section{REFERENCES}

1. Lee JJ, Lee HM, Lim HB, Seo SW, Ahn HB, Lee SB. Learning curve for endoscopic endonasal dacryocystorhinostomy. Korean J Ophthalmol 2017; 31(4): 299-305.

2. Kingdom TT, Barham HP, Durairaj VD. Long-term outcomes after endoscopic dacryocystorhinostomy without mucosal flap preservation. Laryng 2020; 130(1): 12-17.

3. Ramakrishnan VR, Hink EM, Durairaj VD, Kingdom TT. Outcomes after endoscopic dacryocystorhinostomy without mucosal flap preservation. Am J Rhinol 2007; 21(6): 753-757.

4. Marcet MM, Kuk AK, Phelps PO. Evidence-based review of surgical practices in endoscopic endonasal dacryocystorhinostomy for primary acquired nasolacrimal duct obstruction and other new indications. Curr Opin Ophthalmol 2014; 25(5): 443-448.

5. Kedilaya YJ, Chacko A, Poorey VK. Improving the results of endonasal dacryocystorhinostomy with mitomycin c application: a prospective case-control study. Ind J Otolaryngol Head Neck Surg 2018; 70(4): 477-481.

6. Amadi AJ. Endoscopic DCR vs external DCR: What's Best in the Acute Setting?. J Ophthalmic Vis Res 2017; 12(3): 251-253.

7. Caldwell GW. Two new operations for obstruction of the nasal duct. NY State J Med 1893; 57(2): 581-582.

8. West GM. A window resection of the nasal duct in cases of stenosis. Trans Am Ophthalmol Soc 1910; 12(2): 654-658.

9. Halle M. Zur intranasalen operation am tranensack. Arch Laryngol Rhinol 1914; 28(2): 256-266.

10. McDonogh M, Meiring JH. Endoscopic transnasal dacryocystorhinostomy. J Laryngol Otol 1989; 100(1): 585-587.

11. Balikoglu-Yilmaz M, Yilmaz T, Taskin U, Taskapili M, Akcay M, Oktay MF, et al. Prospective comparison of 3 dacryocystorhinostomy surgeries: external versus endoscopic versus transcanali- 


\section{Endonasal Endoscopic Dacryocystorhinostomy}

cular multidiode laser. Ophthalmic Plast Reconstr Surg 2015; 31(1): 13-18.

12. Yigit O, Samancioglu M, Taskin U, Ceylan S, Eltutar K, Yener M. External and endoscopic dacryocystorhinostomy in chronic dacryocystitis: comparison of results. Eur Arch Otorhinolaryngol 2007; 264(8): 879-885.

13. Huang J, Malek J, Chin D, Snidvongs K, Wilcsek G, Sacks R, et al. Systematic review and meta-analysis on outcomes for endoscopic versus external dacryocystorhinostomy. Orbit 2014; 33(2): 81-90.

14. Das SK, Sarkar P, Dan A, Boral K, Basak B, Banerjee SN. Endoscopic dacryocystorhinostomy: a study at IPGMER, Kolkata. Indian J Otolaryngol Head Neck Surg 2013; 65 (Suppl-2): 366-370.

15. Shahraki K, Makateb A, Shirzadi K, Khosravifard K. Frequency of bacterial samples from patients with chronic acquired nasolacrimal duct obstruction. Med Arch 2016; 70(6): 433-436.

16. Zuhair Al-Asadi S, Muhammed Al-Abbasy A. Efficacy of diode laser transcanalicular dacryocystorhinostomy for the treatment of acquired nasolacrimal duct obstruction. Gomal J Med Sci 2011; 9(2): 64-68.

17. Ahmed U, Khan A, Agha H, Usman A. External Dacryocystorhinostomy or endonasal endoscopic dacryocystorhinostomy, results of surgery with multi-disciplinary team approach. Ophthalmol Update 2018; 16(2): 613-616.
18. Aslam MA, Shahzad J. Is endonasal endoscopic Dacryocystorhinostomy is a safe and successful procedure: an audit of 106 cases. Isra Med J 2019; 11(5): 376-379.

19. Ali MJ, Psaltis AJ, Murphy J, Wormald PJ. Powered endoscopic dacryocystorhinostomy: a decade of experience. Ophthal Plast Reconstr Surg 2015; 31(3): 219-212.

20. Majhi S, Sharma A. Evaluation of role of mitomycin $C$ in the cases of nasolacrimal duct blockage undergoing endoscopic dacryocystorhinostomy. Ind J Otolaryngol Head Neck Surg 2019; 71(Suppl-3): 1981-1985.

21. Orsolini MJ, Schellini SA, Souza Meneguim RLF, Catâneo AJM. Success of endoscopic dacryocystorhinostomy with or without stents: systematic review and meta-analysis. Orbit 2019; 29(2):1-8.

22. Ciğer E, Balci MK, Arslanoğlu S, Eren E. Endoscopic-Powered Dacryocystorhinostomy without Stenting: Long-term Outcomes of 120 Procedures. Am J Rhinol Allergy 2018; 32(4): 303-309.

23. Leong SC. A systematic review of outco-mes after dacryocystorhinostomy in adults. Am J Rhinol Allergy 2010; 24(1): 81-90.

24. Figueira E, Al Abbadi Z, Malhotra R, Wilcsek G, Selva D. Frequency of simultaneous nasal procedures in endoscopic dacryocystorhinostomy. Ophthal Plast Reconstr Surg 2014; 30(1): 40-43.

25. Hodgson N, Bratton E, Whipple K, Priel A, Oh SR, Fante RG Outcomes of endonasal dacryocystorhinostomy without mucosal flap preservation. Ophthal Plast Reconstr Surg 2014; 30(1): 24-27. 